\title{
Thermodynamic Complexity of Sulfated Zirconia Catalysts
}

\author{
Naiwang Liu ${ }^{\text {a, b }}$, Xiaofeng Guo ${ }^{\text {c }}$, Alexandra Navrotsky ${ }^{\text {b, }}$, Li Shi ${ }^{\text {a, }}$, and Di Wu ${ }^{\text {b, d, * }}$ \\ ${ }^{a}$ State Key Laboratory of Chemical Engineering, East China University of Science and \\ Technology, Shanghai 200237, China
}

${ }^{\mathrm{b}}$ Peter A. Rock Thermochemistry Laboratory and NEAT ORU, University of California, Davis, One Shields Avenue, Davis, California 95616, United States

${ }^{\mathrm{c}}$ Earth System Observations, Earth and Environmental Sciences Division, Los Alamos National Laboratory, Los Alamos, New Mexico 87545, United States

$\mathrm{d}$ The Gene and Linda Voiland School of Chemical Engineering and Bioengineering, Washington State University, Pullman, Washington 99163, United States

\section{Corresponding Authors}

anavrotsky@ucdavis.edu (Alexandra Navrotsky)

yyshi@ecust.edu.cn (Li Shi)

d.wu@wsu.edu (Di Wu) 


\begin{abstract}
A series of sulfated zirconia (SZ) catalysts was synthesized by immersion of amorphous zirconium hydroxide in sulfuric acid of various concentrations (1 to $5 \mathrm{~N}$ ). These samples were fully characterized by X-ray diffraction (XRD), thermogravimetric analysis and mass spectrometry (TGA-MS), and aqueous sulfuric acid immersion and high temperature oxide melt solution calorimetry. We investigated the enthalpies of the complex interactions between sulfur species and the zirconia surface $\left(\Delta H_{s z}\right)$ for the sulfated zirconia precursor (SZP), ranging from $109.46 \pm 7.33(1 \mathrm{~N})$ to $-42.50 \pm 0.89(4 \mathrm{~N}) \mathrm{kJ} / \mathrm{mol} \mathrm{S} . \Delta H_{s z}$ appears to be a roughly exponential function of sulfuric acid concentration. On the other hand, the enthalpy of SZ formation $\left(\Delta H_{f}\right)$, becomes more exothermic linearly as sulfur surface coverage increases, from $-147.90 \pm 4.16$ $\left(2.29 \mathrm{~nm}^{-2}\right)$ to $-317.03 \pm 4.20\left(2.14 \mathrm{~nm}^{-2}\right) \mathrm{kJ} / \mathrm{mol} \mathrm{S}$, indicating stronger sulfur species - zirconia bonding.
\end{abstract}

\title{
KEYWORDS
}

Sulfated zirconia, enthalpy of formation, heterogeneous catalysis, thermodynamics, calorimetry, olefins conversion, stability and activity 


\section{INTRODUCTION}

Heterogeneous catalysis plays a critical role in modern chemical industry. Unless the catalytic active components are stabilized through subtle, thermodynamically favorable interactions on a substrate they are generally not robust for industrial applications [1]. Wellknown examples include supported metal nanoclusters [2] and dispersed super-acidic moieties [3]. Thus, knowing the strength of interactions and bonding between molecular-level active catalytic species and support materials is of great importance for understanding and optimizing parameters for successful catalyst synthesis and operation.

Because of its very strong surface acidity, sulfated zirconia (SZ) has been applied extensively in the chemical industry as an acid catalyst [4]. Applications include isomerization [5], hydrocracking [6], alkylation [7, 8] and oligomerization of hydrocarbons [9]. Numerous experimental (spectroscopy, diffraction and microscopy) [10-14] and computational (density functional theory and molecular dynamics) $[15,16]$ studies have been performed to explore the specific binding, surface assembly and/or structure, and catalytic activity of SZ. However, few studies have explored the energetics of SZ materials, including sulfur species - zirconia interactions in aqueous solutions during catalyst precursor (SZP) synthesis (enthalpy of immersion of zirconia in sulfuric acid), the material phase evolution during calcination, and the energetics of formation of the as-made SZ catalyst.

In this context, calorimetry is a powerful tool to probe the interactions and bonding energetics on surfaces or at interfaces. Recently, we have performed a series of systematic thermochemical studies on small molecule - surface interactions using immersion, solution and/or gas adsorption calorimetry [17-21]. In addition, the bonding energetics of $\mathrm{CO}_{2}[22,23]$, $\mathrm{CH}_{4}$ [24], water, ethanol [25], N,N-dimethylformamide (DMF) and N,N-diethylformamide (DEF) 
[26] was also investigated for various metal-organic frameworks (MOFs). Most of these bonding or interaction enthalpies were found to be functions of adsorbate molecule coverage.

Here, we take a similar approach to evaluate interactions in the SZ catalyst. Combining sulfuric acid immersion calorimetry, high temperature oxide melt solution calorimetry, and thermogravimetric analysis and mass spectrometry (TGA-MS), we determined the magnitude of sulfur species - zirconia surface interactions (enthalpy of immersion) under SZP synthesis conditions at room temperature. Additionally, we identified two groups of energetically distinct sulfur species adsorbed on the SZP surface. Further, we quantified the enthalpies of SZ formation $\left(\Delta H_{f}\right)$ from constitute oxides. These energetics were determined, interpreted and discussed as functions of sample treatment temperature, sulfuric acid concentration, and sulfur species coverage. These measurements provide thermodynamic insights for sulfation of zirconia surfaces in both catalytic material synthesis and applications.

\section{MATERIALS AND METHODS}

\subsection{Synthesis of sulfated zirconia (SZ)}

Zirconium hydroxide $(\mathrm{Z})$ was synthesized via a sol-gel method. Ammonium hydroxide solution $\left(\sim 25 \%\right.$ v/v) was dripped into zirconium oxychloride $\left(\mathrm{ZrOCl}_{2} \cdot 8 \mathrm{H}_{2} \mathrm{O}\right)$ aqueous solution kept at $60{ }^{\circ} \mathrm{C}$ under vigorous stirring until the $\mathrm{pH}$ reached 8.0. This solution was aged at room temperature for 12 hours followed by filtration. The precipitation, zirconium hydroxide, was collected and washed 5 times to maximize chloride ion removal. The dried zirconium hydroxide powder was then subjected to sulfation immersion/impregnation for 1 hour, in which sulfuric acid solutions of different concentration from 1 to $5 \mathrm{~N}$ were used. After another round of filtration and drying, we obtained the sulfated zirconia precursor (SZP). The final product, 
sulfated zirconia (SZ) was achieved through calcination of SZP at $650{ }^{\circ} \mathrm{C}$ in air for 2 hours. For clarity, the final treatment temperature is marked after each sample name in the tables. Hence, the zirconium hydroxide, sulfated zirconia precursor and sulfated zirconia were denoted with temperature labeled as Z-25, SZP-25 and SZ-650.

\subsection{Characterization}

Powder X-ray diffraction (XRD) patterns were collected using a Bruker-AXS-D8 Advance diffractometer (Bruker, AXS, Inc., Madison, WI) operated at $40 \mathrm{kV}$ and $40 \mathrm{~mA}(\mathrm{Cu}$ $\mathrm{K} \alpha, \lambda=0.15406 \mathrm{~nm}$ ). Data were acquired in the $2 \theta$ range of $20-70^{\circ}$ (step size $0.02^{\circ}$ and $1 \mathrm{~s}$ per step). The sample phase distribution and crystallite size were quantified by Rietveld refinement using JADE 6.1 software.

The Brunauer-Emmett-Teller (BET) surface areas were measured using a Gemini 2360 instrument (Micromeritics, Norcross, GA). Prior to BET analysis, samples were degassed at 200 ${ }^{\circ} \mathrm{C}$ under vacuum for 12 hours. All the measurements were triplicated to ensure reproducibility.

\subsection{Thermogravimetric analysis and mass spectrometry (TGA-MS)}

Thermogravimetric analysis (TGA) was carried out using a Netzsch STA 449 instrument (NETZSCH, Germany). About $20 \mathrm{mg}$ sample was pressed into a pellet and heated from 30 to $1000{ }^{\circ} \mathrm{C}\left(10{ }^{\circ} \mathrm{C} / \mathrm{min}\right)$ under argon flow $(40 \mathrm{ml} / \mathrm{min})$. The evolved gas was introduced into a mass spectrometer (Cirrus-2, MKS Instruments, UK, Ltd.) through a capillary tube heated at $100{ }^{\circ} \mathrm{C}$. Each TGA-MS analysis was corrected by recording a baseline with empty platinum crucible. The mass spectrometer was calibrated using calcium oxalate monohydrate $\left(\mathrm{CaC}_{2} \mathrm{O}_{4} \cdot \mathrm{H}_{2} \mathrm{O}\right)$, which has known water content.

\subsection{Immersion calorimetry}


The immersion enthalpies of zirconia in sulfuric acid solutions ( 1 to $5 \mathrm{~N}$ ) were measured using a Setaram C80 microcalorimeter equipped with a custom-made dropping tube. Each sample was hand-pressed into a pellet (about $10 \mathrm{mg}$ ), weighed on a microbalance, and dropped from room temperature into the solution at $25{ }^{\circ} \mathrm{C}$. The drop resulted in a heat effect (calorimetric peak) associated with the reaction between the solid sample and the solution. Immersion calorimetry on each sample was repeated at least eight times to ensure reproducibility, which is shown as error bars (2 standard deviations of the mean) in the figures. Prior to immersion calorimetry, samples were outgassed at $200{ }^{\circ} \mathrm{C}$ overnight to maximize removal of adsorbed species.

\subsection{High-temperature oxide melt solution calorimetry}

The drop solution enthalpies of all samples in molten sodium molybdate $\left(3 \mathrm{Na}_{2} \mathrm{O} \cdot 4 \mathrm{MoO}_{3}\right)$ at $703{ }^{\circ} \mathrm{C}$ were measured using a custom-made Tian-Calvet twin microcalorimeter. The detailed methodology was described elsewhere [27]. Sample pellets ( $5 \mathrm{mg})$ were hand-pressed and dropped from ambient conditions into the solvent in a platinum crucible in the hot calorimeter. The calorimetric assembly was flushed using oxygen $(50 \mathrm{~mL} / \mathrm{min})$ to maintain oxidizing environment and the solvent was bubbled with oxygen $(0.5 \mathrm{~mL} / \mathrm{min})$ to promote sample dissolution and to propel evolved gases. All samples were degassed at $200{ }^{\circ} \mathrm{C}$ overnight before calorimetric measurement. The calorimeter was calibrated using the known heat content of high purity alpha alumina (Alfa Aesar, $99.997 \%$ ). The thermodynamic cycles used to derive the enthalpy of SZ formation $\left(\Delta H_{f}\right)$ are listed in Table 1.

\subsection{Catalytic activity test}

An alkylation reaction in which olefins react with aromatics leading to reduced olefin 
Table 1. Thermodynamic cycles for sulfate moiety - zirconia surface bonding energies.

\begin{tabular}{ll}
\hline \multicolumn{1}{c}{ Reaction Formula ${ }^{\mathrm{a}}$} & \multicolumn{1}{c}{ Reaction Enthalpy } \\
\hline $\mathrm{ZrO}_{2} \cdot \mathrm{xSO}_{3} \cdot \mathrm{yH}_{2} \mathrm{O}\left(\right.$ tetragonal/ads/ads, $\left.25^{\circ} \mathrm{C}\right) \rightarrow$ & \\
$\mathrm{ZrO}_{2}\left(\right.$ sol, $\left.703{ }^{\circ} \mathrm{C}\right)+\mathrm{yH}_{2} \mathrm{O}\left(\mathrm{g}, 703{ }^{\circ} \mathrm{C}\right)+\mathrm{xSO}_{3}\left(\mathrm{sol}, 703{ }^{\circ} \mathrm{C}\right){ }^{\mathrm{b}}$ & $\Delta H_{d s}$ \\
$\mathrm{ZrO}_{2}\left(\right.$ tetragonal, $\left.25{ }^{\circ} \mathrm{C}\right) \rightarrow \mathrm{ZrO}_{2}\left(\mathrm{sol}, 703{ }^{\circ} \mathrm{C}\right)$ & $\Delta H_{1}{ }^{\mathrm{c}}$ \\
$\mathrm{H}_{2} \mathrm{O}\left(\mathrm{ads}, 25{ }^{\circ} \mathrm{C}\right) \rightarrow \mathrm{H}_{2} \mathrm{O}\left(\mathrm{g}, 25{ }^{\circ} \mathrm{C}\right)$ & $\Delta H_{2}{ }^{\mathrm{d}}$ \\
$\mathrm{H}_{2} \mathrm{O}\left(\mathrm{g}, 25{ }^{\circ} \mathrm{C}\right) \rightarrow \mathrm{H}_{2} \mathrm{O}\left(\mathrm{g}, 703{ }^{\circ} \mathrm{C}\right)$ & $\Delta H_{3}{ }^{\mathrm{e}}$ \\
$\mathrm{SO}_{3}\left(\mathrm{~g}, 25^{\circ} \mathrm{C}\right) \rightarrow \mathrm{SO}_{3}\left(\mathrm{sol}, 703{ }^{\circ} \mathrm{C}\right)$ & $\Delta H_{4}{ }^{\mathrm{f}}$ \\
$\mathrm{SO}_{3}\left(\mathrm{ads}, 25^{\circ} \mathrm{C}\right) \rightarrow \mathrm{SO}_{3}\left(\mathrm{~g}, 25{ }^{\circ} \mathrm{C}\right)$ & $\Delta H_{f}$ \\
$\Delta H_{f}=\Delta H_{d s}-\Delta H_{1}-\Delta H_{2}-\Delta H_{3}-\Delta H_{4}$ & \\
\hline
\end{tabular}

a "g", “ads" and "sol" denotes "gas", “adsorption" and "in sodium molybdate solution", respectively.

${ }^{\mathrm{b}}$ Ref. Majzlan et al. [28] and Drouet et al. [29]

${ }^{\mathrm{c}} \Delta H_{d s}$ and $\Delta H_{l}\left(\Delta H_{1}=27.06 \pm 0.71 \mathrm{~kJ} / \mathrm{mol} \mathrm{ZrO}_{2}\right.$ [30] $)$ are drop solution enthalpies of sulfated zirconia (SZ) and nanophase tetragonal zirconia obtained using high temperature oxide melt solution calorimetry, respectively.

${ }^{\mathrm{d}} \Delta H_{2}$ is enthalpy of $\mathrm{H}_{2} \mathrm{O}$ adsorption on sulfated zirconia surface.

${ }^{\mathrm{e}} \Delta H_{3}=25.65 \mathrm{~kJ} / \mathrm{mol} \mathrm{H} \mathrm{H}_{2} \mathrm{O}[30]$

${ }^{\mathrm{f}} \Delta H_{4}$ is drop solution enthalpy for $\mathrm{SO}_{3}$, it cannot be determined directly experimentally but has been calculated from reaction the formation enthalpies of $\mathrm{SO}_{2}$ and $\mathrm{O}_{2}$. According to previous work, $\Delta H_{4}=-217.02 \pm 4.17 \mathrm{~kJ} / \mathrm{mol}[28]$.

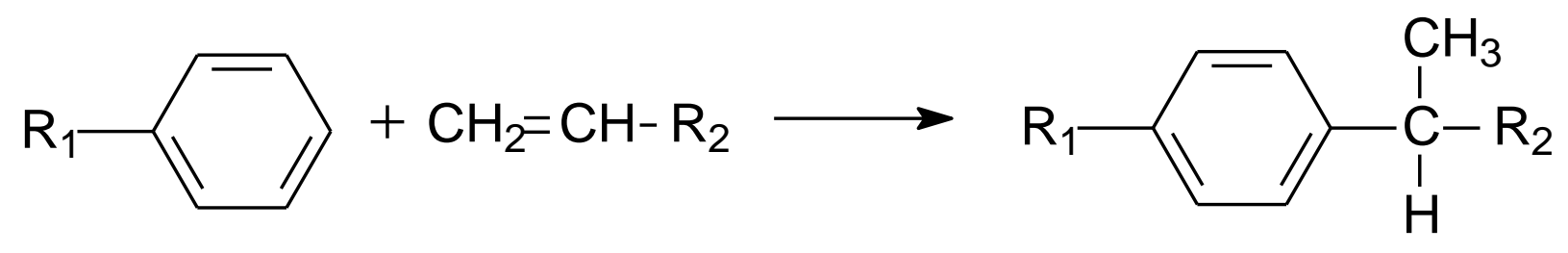

Scheme 1. Alkylation between aromatics and olefins. 
concentration in aromatic liquids (Scheme 1) [31] was employed to test the catalytic activity of SZ treated in different conditions. Alkylation was carried out in a fixed bed tubular micro-reactor equipped with a constant flow pump to enable precise flow rate and temperature control. Catalyst (SZ, $2 \mathrm{~mL}$ ) was loaded into the micro-reactor, the spare space of which was filled with quartz sand (space filler). The tests were performed at 1.0 MPa with a liquid hourly space velocity (LHSV) of $30 \mathrm{~h}^{-1}$ [32]. Bromine Index is an indicator of olefin content in aromatics. According to ASTM standard D 2710-92, it is defined as the amount of bromine (mg) consumed by $100 \mathrm{~g}$ of hydrocarbon. The inlet and effluent liquids of the fixed bed tubular micro-reactor were monitored by a Bromine Index Analyzer (OSC 971KK 101, Ogawa Seiki Co., Ltd.). The olefin conversion rate, $X$, was calculated as $X=\left(N_{i}-N_{o}\right) / N_{i} \times 100 \%$, in which $\mathrm{N}_{\mathrm{i}}$ and $\mathrm{N}_{\mathrm{o}}$ correspond to the bromine index of the inlet and effluent liquids, respectively. The specific olefin and aromatic compounds involving in the alkylation reactions and their contents are listed in Table 2 [32].

Table 2. The specific olefin and aromatic compounds $(\mathrm{BI}=1035)$ involving in the alkylation reactions and their contents.

\begin{tabular}{lr}
\hline Compound & Content (wt\%) \\
\hline Nonaromatics & 2.08 \\
Benzene & 0.06 \\
Toluene & 0.05 \\
Ethylbenzene & 6.85 \\
p-Xylene & 8.92 \\
m-Xylene & 18.98 \\
o-Xylene & 12.25 \\
$\mathrm{C}_{9}$ & 37.12 \\
$\mathrm{C}_{10}$ and $\mathrm{C}_{10^{+}}$ & 13.69 \\
\hline
\end{tabular}

\section{RESULTS}

\subsection{Characterization}

The TG and DTG traces and corresponding MS curves of SZP-25 (4 N) are presented in 
Figure 1 and 2. MS signals were observed for $\mathrm{M} / \mathrm{Z}=18,32$ and 64 , which correspond to $\mathrm{H}_{2} \mathrm{O}$, $\mathrm{O}_{2}$ and $\mathrm{SO}_{2}$, respectively. Thermal analysis of SZP-25 in argon results in a series of reactions, which can be categorized into two groups. $\mathrm{H}_{2} \mathrm{O}$ is desorbed from the SZP surface first. There appear to be two types of energetically distinct $\mathrm{H}_{2} \mathrm{O}$ species. Physisorbed $\mathrm{H}_{2} \mathrm{O}$ is released at about $120{ }^{\circ} \mathrm{C}$, while liberation of chemisorbed $\mathrm{H}_{2} \mathrm{O}$ takes place between 300 and $500{ }^{\circ} \mathrm{C}$. This is followed by decomposition of sulfur species from 600 to $850{ }^{\circ} \mathrm{C}$, leading to evolution of $\mathrm{SO}_{2}$ and $\mathrm{O}_{2}\left(\mathrm{SO}_{2}: \mathrm{O}_{2} \sim 2: 1\right)$. The position, shape and area of MS peaks for $\mathrm{H}_{2} \mathrm{O}, \mathrm{O}_{2}$ and $\mathrm{SO}_{2}$ correspond very well with the TGA and DTG curves (Figures 1 and 2).

Table 3. Post immersion calorimetry SZP sample compositions and enthalpies of sulfur species zirconia interactions $\left(\Delta H_{S Z}\right.$, with different units). These enthalpies data come directly from immersion calorimetry.

\begin{tabular}{|c|c|c|c|c|}
\hline Sample & Composition & $\begin{array}{c}\Delta H_{S Z} \\
\left(\mathrm{~kJ} / \mathrm{mol} \mathrm{ZrO}_{2}\right) \\
\end{array}$ & $\begin{array}{c}\Delta H_{S Z} \\
\left(\mathrm{~J} / \mathrm{g} \mathrm{ZrO}_{2}\right) \\
\end{array}$ & $\begin{array}{c}\Delta H_{S Z} \\
(\mathrm{~kJ} / \mathrm{mol} \mathrm{S})\end{array}$ \\
\hline SZP-25 (1 N) & $\mathrm{ZrO}_{2} \cdot 0.07 \mathrm{SO}_{3} \cdot 0.49 \mathrm{H}_{2} \mathrm{O}$ & $-7.94 \pm 0.53$ & $-57.54 \pm 3.85$ & $-109.46 \pm 7.33$ \\
\hline SZP-25 (2N) & $\mathrm{ZrO}_{2} \cdot 0.09 \mathrm{SO}_{3} \cdot 0.56 \mathrm{H}_{2} \mathrm{O}$ & $-7.79 \pm 0.60$ & $-55.50 \pm 4.29$ & $-87.64 \pm 6.78$ \\
\hline SZP-25 (3 N) & $\mathrm{ZrO}_{2} \cdot 0.15 \mathrm{SO}_{3} \cdot 1.03 \mathrm{H}_{2} \mathrm{O}$ & $-8.09 \pm 0.53$ & $-52.35 \pm 3.41$ & $-51.31 \pm 3.35$ \\
\hline SZP-25 (4 N) & $\mathrm{ZrO}_{2} \cdot 0.20 \mathrm{SO}_{3} \cdot 1.09 \mathrm{H}_{2} \mathrm{O}$ & $-8.55 \pm 0.18$ & $-53.78 \pm 1.13$ & $-42.50 \pm 0.89$ \\
\hline SZP-25 (5 N) & $\mathrm{ZrO}_{2} \cdot 0.20 \mathrm{SO}_{3} \cdot 1.11 \mathrm{H}_{2} \mathrm{O}$ & $-8.64 \pm 0.28$ & $-54.17 \pm 1.78$ & $-42.55 \pm 1.40$ \\
\hline
\end{tabular}

Table 4. Sample characterization and thermodynamic data for high temperature oxide melt solution calorimetry, including enthalpies of dissolution directly measured by calorimetry, $\Delta H_{d s}$ and enthalpies of SZ formation $\Delta H_{f}$ : calculated using thermodynamic cycle listed in Table 1.

\begin{tabular}{cccccc}
\hline Sample & Composition & $\begin{array}{c}\text { Surface Area } \\
\left(\mathrm{m}^{2} / \mathrm{g}\right)\end{array}$ & $\begin{array}{c}\mathrm{S} \text { coverage } \\
\left(/ \mathrm{nm}^{2}\right)\end{array}$ & $\begin{array}{c}\Delta H_{d s} \\
\left(\mathrm{~kJ} / \mathrm{mol} \mathrm{ZrO}_{2}\right)\end{array}$ & $\begin{array}{c}\Delta H_{f} \\
(\mathrm{~kJ} / \mathrm{mol} \mathrm{S})\end{array}$ \\
\hline $\mathrm{SZ}-650(1 \mathrm{~N})$ & $\mathrm{ZrO}_{2} \cdot 0.02 \mathrm{SO}_{3} \cdot 0.07 \mathrm{H}_{2} \mathrm{O}$ & $56.19 \pm 0.18$ & 2.29 & $18.34 \pm 0.56$ & $-317.03 \pm 4.20$ \\
$\mathrm{SZ}-650(2 \mathrm{~N})$ & $\mathrm{ZrO}_{2} \cdot 0.03 \mathrm{SO}_{3} \cdot 0.07 \mathrm{H}_{2} \mathrm{O}$ & $67.18 \pm 0.19$ & 2.28 & $16.79 \pm 0.43$ & $-305.30 \pm 4.18$ \\
$\mathrm{SZ}-650(3 \mathrm{~N})$ & $\mathrm{ZrO}_{2} \cdot 0.03 \mathrm{SO}_{3} \cdot 0.09 \mathrm{H}_{2} \mathrm{O}$ & $73.68 \pm 0.23$ & 2.20 & $19.66 \pm 0.11$ & $-230.61 \pm 4.16$ \\
$\mathrm{SZ}-650(4 \mathrm{~N})$ & $\mathrm{ZrO}_{2} \cdot 0.04 \mathrm{SO}_{3} \cdot 0.13 \mathrm{H}_{2} \mathrm{O}$ & $83.19 \pm 0.47$ & 2.16 & $22.26 \pm 0.84$ & $-187.81 \pm 4.24$ \\
$\mathrm{SZ}-650(5 \mathrm{~N})$ & $\mathrm{ZrO}_{2} \cdot 0.04 \mathrm{SO}_{3} \cdot 0.13 \mathrm{H}_{2} \mathrm{O}$ & $84.85 \pm 0.38$ & 2.14 & $23.47 \pm 0.43$ & $-147.90 \pm 4.16$ \\
\hline
\end{tabular}


The $\mathrm{SO}_{2}$ MS signal of SZP-25 (4 N) was further interpreted in detail to reveal the energetic insights into sulfur species - zirconia surface interactions in SZ catalyst synthesis (see Figure 3). SZP-25 (4 N) presents two overlapped $\mathrm{SO}_{2} \mathrm{MS}$ peaks upon heating to $1000{ }^{\circ} \mathrm{C}$. Applying Gaussian multi-peak fitting, we were able to split this signal into two peaks (Figure 3A). The first peak is sharp, centered at approximately $650{ }^{\circ} \mathrm{C}$, while the second peak is broad, spanning 600 to $850{ }^{\circ} \mathrm{C}$. We also attempted to separate these two peaks by "quenching" the SZ sample at about $650{ }^{\circ} \mathrm{C}$, followed by another round of TGA-MS examination using the same experimental conditions (see Figure $3 \mathrm{~B}$ and $\mathrm{C}$ ). These results clearly suggest two types of energetically distinct sulfuric components on $\mathrm{ZrO}_{2}$.

The XRD patterns of Z-25, SZP-25, Z-650, SZ-650, SZ-720 and Z-1000 are plotted in Figure 4. These SZP and SZ samples had been prepared using $4 \mathrm{~N}$ sulfuric acid. At $25{ }^{\circ} \mathrm{C}$, both Z-25 and SZP-25 are amorphous. Upon calcination at $650{ }^{\circ} \mathrm{C}$ in air, Z-650 crystallized to monoclinic zirconia, while SZ-650 became a mixture of monoclinic and tetragonal phases. SZ720 became completely tetragonal as temperature increased to $720{ }^{\circ} \mathrm{C}$. Ultimately, all samples became monoclinic after calcination at $1000^{\circ} \mathrm{C}$. Sample compositions are listed in Table 3 and 4. BET surface areas for all samples are listed in Table 4. The sample surface area tends to increase as sulfuric acid concentration increases, ranging from $56.19 \pm 0.18(1 \mathrm{~N})$ to $84.85 \pm 0.38(5 \mathrm{~N})$ $\mathrm{m}^{2} / \mathrm{g}$.

The MS traces, collected from room temperature to $1000{ }^{\circ} \mathrm{C}$, of SZP-25 and SZ-650 prepared with sulfuric acid of different concentration $\left(\mathrm{C}_{\mathrm{s}}=1\right.$ to $\left.5 \mathrm{~N}\right)$ are presented in Figure 5 . The MS profiles of SZP-25 and SZ-650 exhibit distinctly different behavior as a function of $\mathrm{C}_{\mathrm{s}}$. Generally, the loading of sulfur species on the SZP-25 surface $\left(\mathrm{C}_{\text {surface }}\right)$ is proportional to the sulfuric acid concentration $\mathrm{C}_{\mathrm{s}}$. There are two peaks for SZP-25 samples. As $\mathrm{C}_{\mathrm{s}}$ increases, the 
height or intensity of the first peak centered at about $650{ }^{\circ} \mathrm{C}$ increases. In sharp contrast, there is only one peak for SZ-650 samples. The MS intensity and peak area for SZ-650 samples do not change for $\mathrm{C}_{\mathrm{s}}$ higher than $2 \mathrm{~N}$.

\subsection{Immersion calorimetry}

The immersion calorimetry data were plotted in Figure 6. All immersion enthalpies are exothermic, confirming stabilizing surface interactions between zirconia and sulfate species. The enthalpy of immersion of pure zirconia (Z-25) tends to become less exothermic as the concentration of sulfuric acid increases from 1 to $5 \mathrm{~N}$, ranging from $-109.46 \pm 7.33(1 \mathrm{~N})$ to $42.50 \pm 0.89(4 \mathrm{~N}) \mathrm{kJ}$ per mole of sulfur unit $(\mathrm{kJ} / \mathrm{mol} \mathrm{S})$. This plot levels at about $-42 \mathrm{~kJ} / \mathrm{mol} \mathrm{S}$ and further increase of sulfuric acid concentration above $3 \mathrm{~N}$ does not lead to less exothermic enthalpy of immersion.

\subsection{High temperature oxide melt solution calorimetry}

The enthalpy of drop solution $\left(\Delta \mathrm{H}_{\mathrm{ds}}, \mathrm{kJ} / \mathrm{mol} \mathrm{ZrO}_{2}\right)$ tends to be more endothermic, values ranging from $18.34 \pm 3.04$ to $23.47 \pm 1.85 \mathrm{~kJ} / \mathrm{mol} \mathrm{ZrO}_{2}$, as $\mathrm{C}_{\mathrm{s}}$ increases from 1 to $5 \mathrm{~N}$. Considering both sulfation and hydration factors and using the thermodynamic cycle listed in Table 1, we were able to calculate the enthalpy of SZ formation from constitute oxides $\left(\Delta \mathrm{H}_{\mathrm{f}}\right.$,

$\mathrm{kJ} / \mathrm{mol} \mathrm{S}$ ). The SZ formation enthalpy becomes more exothermic as the sulfur coverage increases, ranging from $-317.03 \pm 4.20$ to $-147.90 \pm 4.16 \mathrm{~kJ} / \mathrm{mol} \mathrm{S}$ (Figure 7). From a thermodynamic standpoint, this is reasonable in that, at lower sulfur coverage, only the more strongly interacting sites are filled, while as coverage increases, states less favorable in energy, or representing weaker interactions among sulfate moieties rather than stronger interactions with the surface, become occupied. This trend parallels that seen in immersion enthalpies. 


\subsection{Catalytic activity test}

Figures 8 and 9 show the olefins conversion as a function of the time on stream (TOS). Without anchored sulfur species, the bare zirconia surface does not have catalytic activity. All SZ samples show decreasing olefin conversion as a function of TOS. For a particular TOS, the olefin conversion increases as the calcination temperature increases from $500{ }^{\circ} \mathrm{C}$ to $650{ }^{\circ} \mathrm{C}$. Beyond $700{ }^{\circ} \mathrm{C}$, the $\mathrm{SZ}$ catalysts suffer from significant deactivation due to loss of sulfur species (Figure 8). The SZ samples treated by sulfuric acid with higher concentration show better olefin conversion at the same TOS (Figure 9). The catalytic activity enhancement reaches a maximum at $\mathrm{C}_{\mathrm{s}}=4 \mathrm{~N}$. Further increase of $\mathrm{C}_{\mathrm{s}}$ does not result in better performance.

\section{DISCUSSION}

\subsection{Surface - structure - activity relations: calcination of SZP-25 (4 N)}

SZP-25 (4 N) was reported to have optimized performance for conversion of olefins (\%) [8]. TGA-MS analysis was carried out on this sample to mimic the calcination process in SZ catalyst synthesis. Our results highlight the interplay and competition between surface chemistry and structural evolution as a function of temperature. The desorption/decomposition of the sample occurs in two major temperature ranges (Figure 1 and 2). The first step takes place between 100 and $300{ }^{\circ} \mathrm{C}$ due to slow yet noticeable desorption of water. In this temperature range, dehydration does not result in phase transition (see Figure 4). Although it is difficult to differentiate physisorbed and chemisorbed water on the TGA trace, clear signal splitting can be identified from the MS curve of water (Figure 2).

In sharp contrast, in the second step $\left(600\right.$ to $\left.850{ }^{\circ} \mathrm{C}\right)$ both significant weight loss on TGA curve, and well resolved $\mathrm{SO}_{2}$ and $\mathrm{O}_{2} \mathrm{MS}$ traces corresponding to detachment of sulfur species 
are observed. In this range, the XRD patterns of $\mathrm{SZ}$ at $650{ }^{\circ} \mathrm{C}$ (monoclinic and tetragonal) and $720{ }^{\circ} \mathrm{C}$ (tetragonal) strongly suggest that sulfur removal not only leads to sulfur species decomposition on the surface, but also significantly modifies the bulk zirconia structure (Figure 4). For pure zirconia heated at $650{ }^{\circ} \mathrm{C},(\mathrm{Z}-650)$ tetragonal phase is not observed. This strongly suggests that the surface bonded sulfur species play a crucial role in zirconia phase selection at high temperature $\left(600\right.$ to $\left.850{ }^{\circ} \mathrm{C}\right)$ through significant modification of the structure and energetic states of the surface. Indeed, various studies report that the tetragonal phase is necessary for SZ catalytic activity [33], especially for isomerization of hydrocarbons, for which sulfated monoclinic zirconia exhibits undetectable activity. Similar behavior, with little catalytic activity for SZ-500 (monoclinic), was observed in the alkylation reactions (olefins removal from aromatics) carried out in the present study (Figure 8). Moreover, the well-separated sulfur MS peaks of SZP-25 (4N) indicate that there are two groups of energetically distinct sulfate species on zirconia surface as a function of sulfur loading (Figure 2). These can be identified as the sulfate moieties directly adsorbed through chemisorption before sulfate monolayer formation, and the subsequent, presumably attached through hydrogen bonding, sulfur species beyond the monolayer. The molar ratio of monolayer sulfur to loosely attached sulfur is approximately $1: 1$ (Figure 3).

\subsection{Surface energetics of SZ: a function of sulfur species coverage}

Despite numerous investigations, our understanding on the surface chemistry of SZ is still limited due to the intrinsic complexity of the amorphous zirconia surface and the large variety of possible sulfur species. The thermochemical approach offers a unique angle evaluating the general behavior of a population of molecular species on complex, amorphous surfaces. 
The results are in excellent agreement with the simulation and spectroscopy. Using periodic plane wave pseudopotential calculations based on density functional theory (DFT), Haase et al. [15] predicted that at ultra-low coverage there would be three most stable configurations of sulfur species on different surfaces of tetragonal zirconia: a tridentate sulfate ion on the (101) surface $(-322 \mathrm{~kJ} / \mathrm{mol} \mathrm{S})$, a bidentate sulfate complex on the (001) surface (-408 $\mathrm{kJ} / \mathrm{mol} \mathrm{S})$, and a $\mathrm{SO}_{3}$ complex on the (001) surface (-467 kJ/mol S). In this case, the site-isolated monosulfates $\left(\mathrm{SO}_{3}, \mathrm{HSO}_{4}{ }^{-}, \mathrm{SO}_{4}{ }^{2-}\right)$ are well dispersed and directly anchored at the most strongly interacting zirconia surface sites with minimum self-interactions, leading to the most exothermic enthalpy of SZ formation probed by calorimetry (see Figure 7). Subsequently, as the surface coverage increases, sulfur species may react among themselves forming complexes and/or polysulfate species upon calcination. Employing DFT with periodic boundary conditions, Hofmann et al. [16] predicted that at relatively high coverage, as the sulfate loading reached $2 \mathrm{H}_{2} \mathrm{SO}_{4}$ per two surface unit cells (four $\mathrm{Zr}$ sites), transformation from monosulfates $\left(\mathrm{SO}_{3}, \mathrm{HSO}_{4}{ }^{-}\right.$, $\mathrm{SO}_{4}{ }^{2-}$ ) to pyrosulfate, such as $\mathrm{HS}_{2} \mathrm{O}_{7}{ }^{-}$and $\mathrm{S}_{2} \mathrm{O}_{7}{ }^{2-}$, might occur during calcination. Later, Hino et al. [14] carried out XPS analysis, which demonstrated that, at relatively high coverage, the active moieties on the post calcination SZ surface are polysulfate species assembled by three to four sulfur atoms. In addition to the coordination binding of $\mathrm{S}=\mathrm{O}$ with $\mathrm{Zr}$, these polysulfate assemblages form two S-O-Zr ionic bonds with the zirconia surface. Such a spectrum of microscopic configurations from monosulfates to polysulfates is tightly correlated to and supported by the measured heats of formation, which show increasingly exothermic formation enthalpies for SZ with higher sulfur species coverage. This may reflect favorable interactions during formation of complex more polymerized sulfur species. Interestingly, the SZ catalysts with less exothermic enthalpies of formation exhibit better conversion of olefins. This may 
suggest that lower thermodynamic strength of sulfur bonding both to the zirconia surface and among sulfur species may enable easier bond rearrangement and olefin accessibility during catalysis. Further spectroscopic and surface structural evidence is clearly needed to correlate the energetics with specific surface chemistry.

\section{CONCLUSIONS}

Using XRD, TGA-MS, immersion and high-temperature oxide melt drop solution calorimetry, we performed a detailed study on the thermodynamics of two critical topics for sulfated zirconia catalysts, sulfuric acid immersion (catalyst precursor preparation) and sulfate zirconia binding (strength of S-O-Zr bond), as a function of sulfuric acid concentration $\left(\mathrm{C}_{\mathrm{s}}\right)$. The enthalpy of immersion becomes less exothermic as $\mathrm{C}_{\mathrm{s}}$ increases, while the enthalpy of SZ formation tends to be more exothermic linearly as sulfur species coverage increases. These thermochemical insights are tightly correlated to the surface coverage and configuration of sulfur species. In a broader context, knowing such energetic insights is critical to understand catalyst synthesis and active compounds - catalyst support interactions for heterogeneous catalysts. The thermodynamic insights gained here into competitive interactions of sulfur species on zirconia surfaces may enrich our understanding of sulfated zirconia catalysts and their analogues. 


\section{ACKNOWLEGEMENTS}

This work was supported by the U.S. Department of Energy, Office of Basic Energy Sciences, Grant DE-FG02-05ER15667. N.L. thanks the China Scholarship Council for the State Scholarship Fund (No.201506740047). D. W. thanks the institutional funds from the Gene and Linda Voiland School of Chemical Engineering and Bioengineering at Washington State University. The authors also thank Liangjie Fu for helping with the graphical abstract.

\section{AUTHOR INFORMATION}

\section{Corresponding Authors}

anavrotsky@ucdavis.edu (Alexandra Navrotsky)

yyshi@ecust.edu.cn (Li Shi)

d.wu@wsu.edu $(\mathrm{Di} \mathrm{Wu})$ 


\section{REFERENCES}

[1] B.C. Gates, J. Catal. 328 (2015) 72-74.

[2] P. Serna, B.C. Gates, Acc. Chem. Res. 47 (2014) 2612-2620.

[3] M.H. Lim, C.F. Blanford, A. Stein, Chem. Mater. 10 (1998) 467-470.

[4] F.R. Chen, G. Coudurier, J.F. Joly, J.C. Vedrine, J. Catal. 143 (1993) 616-626.

[5] P. Wang, J. Zhang, G. Wang, C. Li, C. Yang, J. Catal. 338 (2016) 124-134.

[6] R.A. Keogh, D. Sparks, J.L. Hu, I. Wender, J.W. Tierney, W. Wang, B.H. Davis, Energy Fuels 8 (1994) 755-762.

[7] E. Vlasov, S. Myakin, M. Sychov, A. Aho, A.Y. Postnov, N. Mal'tseva, A. Dolgashev, S.O. Omarov, D.Y. Murzin, Catal. Lett. 145 (2015) 1651-1659.

[8] J.J. Yao, N.W. Liu, L. Shi, X. Wang, Catal. Commun. 66 (2015) 126-129.

[9] A. Koklin, V.K. Chan, V. Bogdan, Russ. J. Phys. Chem. B 8 (2014) 991-998.

[10] A. Patel, V. Brahmkhatri, N. Singh, Renewable Energy 51 (2013) 227-233.

[11] S. Ardizzone, C.L. Bianchi, Surf. Interface Anal. 30 (2000) 77-80.

[12] F. Babou, G. Coudurier, J.C. Vedrine, J. Catal. 152 (1995) 341-349.

[13] J.F. Haw, J. Zhang, K. Shimizu, T.N. Venkatraman, D.-P. Luigi, W. Song, D.H. Barich, J.B. Nicholas, J. Am. Chem. Soc. 122 (2000) 12561-12570.

[14] M. Hino, M. Kurashige, H. Matsuhashi, K. Arata, Thermochim Acta, 441 (2006) 35-41.

[15] F. Haase, J. Sauer, J. Am. Chem. Soc. 120 (1998) 13503-13512.

[16] A. Hofmann, J. Sauer, J. Phys. Chem. B 108 (2004) 14652-14662.

[17] D. Wu, S.-J. Hwang, S.I. Zones, A. Navrotsky, Proc. Natl. Acad. Sci. USA 111 (2014) 17201725.

[18] D. Wu, A. Navrotsky, Geochim. Cosmochim. Acta 109 (2013) 38-50.

[19] D. Wu, X. Guo, H. Sun, A. Navrotsky, J. Phys. Chem. C 119 (2015) 15428-15433.

[20] H. Sun, D. Wu, X. Guo, B. Shen, J. Liu, A. Navrotsky, J. Phys. Chem. C (2014) 118 (44), 25590-25596.

[21] D. Wu, A. Navrotsky, Proc. Natl. Acad. Sci. USA 112 (2015) 5314-5318.

[22] D. Wu, J.J. Gassensmith, D. Gouvea, S. Ushakov, J.F. Stoddart, A. Navrotsky, J. Am. Chem. Soc. 135 (2013) 6790-6793.

[23] D. Wu, T.M. McDonald, Z. Quan, S.V. Ushakov, P. Zhang, J.R. Long, A. Navrotsky, J. Mater. Chem. A 3 (2015) 4248-4254.

[24] D. Wu, X.F. Guo, H. Sun, A. Navrotsky, J. Phys. Chem. Lett. 6 (2015) 2439-2443.

[25] D. Wu, X.F. Guo, H. Sun, A. Navrotsky, J. Phys. Chem. C 120 (2016) 7562-7567.

[26] Z. Akimbekov, D. Wu, C.K. Brozek, M. Dinca, A. Navrotsky, Phys. Chem. Chem. Phys. 18 (2016) 1158-1162.

[27] A. Navrotsky, J. Am. Ceram. Soc. 97 (2014) 3349-3359.

[28] J. Majzlan, A. Navrotsky, J. Neil, Geochim. Cosmochim. Acta 66 (2002) 1839-1850.

[29] C. Drouet, A. Navrotsky, Geochim. Cosmochim. Acta 67 (2003) 2063-2076.

[30] M.W. Pitcher, S.V. Ushakov, A. Navrotsky, B.F. Woodfield, G. Li, J. Boerio - Goates, B.M. Tissue, J. Am. Ceram. Soc. 88 (2005) 160-167.

[31] N. Liu, X. Pu, L. Shi, Chem. Eng. Sci. 119 (2014) 114-123.

[32] N. Liu, X. Pu, X. Wang, L. Shi, J. Ind. Eng. Chem. 20 (2014) 2848-2857.

[33] C. Morterra, G. Cerrato, F. Pinna, M. Signoretto, J. Catal. 157 (1995) 109-123. 


\section{FIGURE CAPTIONS}

Figure 1. Thermogravimetric analysis (TGA) and differential thermogravimetric analysis (DTG) profiles for SZP-25 (4 N) sample.

Figure 2. Mass spectrometry (MS) curves of water, $\mathrm{SO}_{2}$ and $\mathrm{O}_{2}$ for $\mathrm{SZP}-25(4 \mathrm{~N})$ sample.

Figure 3. Separation of $\mathrm{SO}_{2}$ mass spectrometry (MS) signals for SZP-25 (4 N) sample.

Figure 4. Powder $\mathrm{X}$-ray diffraction (XRD) patterns of A) pure zirconia at $\left.25{ }^{\circ} \mathrm{C}(\mathrm{Z}-25), \mathrm{B}\right)$ sulfated zirconia precursor (SZP-25) $\left.25{ }^{\circ} \mathrm{C}, \mathrm{C}\right)$ pure zirconia at $650{ }^{\circ} \mathrm{C}(\mathrm{Z}-650)$, D) sulfated zirconia at $650{ }^{\circ} \mathrm{C}(\mathrm{SZ}-650)$, E) sulfated zirconia at $720{ }^{\circ} \mathrm{C}(\mathrm{SZ}-720)$, and $\left.\mathrm{F}\right)$ sulfated zirconia at $1000{ }^{\circ} \mathrm{C}(\mathrm{SZ}-1000)$.

Figure 5. $\mathrm{SO}_{2}$ mass spectrometry (MS) signals for A) SZP-25 and B) SZ-650 (1 to $5 \mathrm{~N}$ ) samples.

Figure 6. Enthalpy change for sulfur species - zirconia surface interactions for SZP-25 (4 N) as a function of sulfuric acid concentration.

Figure 7. Enthalpy of SZ formation from constitute oxides for SZ-650 as a function of sulfur species surface coverage.

Figure 8. Olefin conversion rate of SZ catalyst prepared at different temperatures, from 500 to $700{ }^{\circ} \mathrm{C}$.

Figure 9. Olefin conversion rate of SZ catalyst prepared under different sulfuric acid concentration, from 1 to $6 \mathrm{~N}$. 


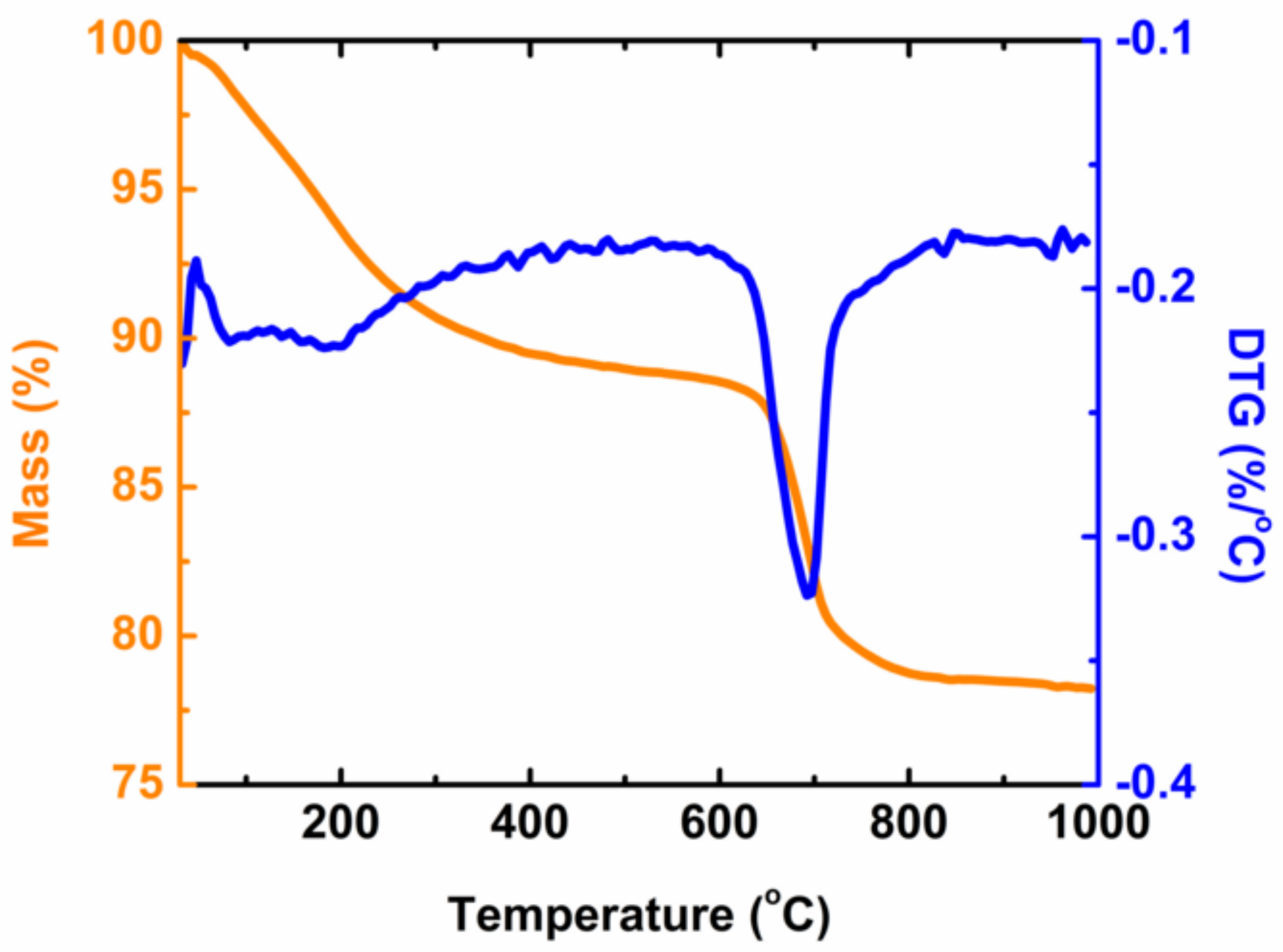




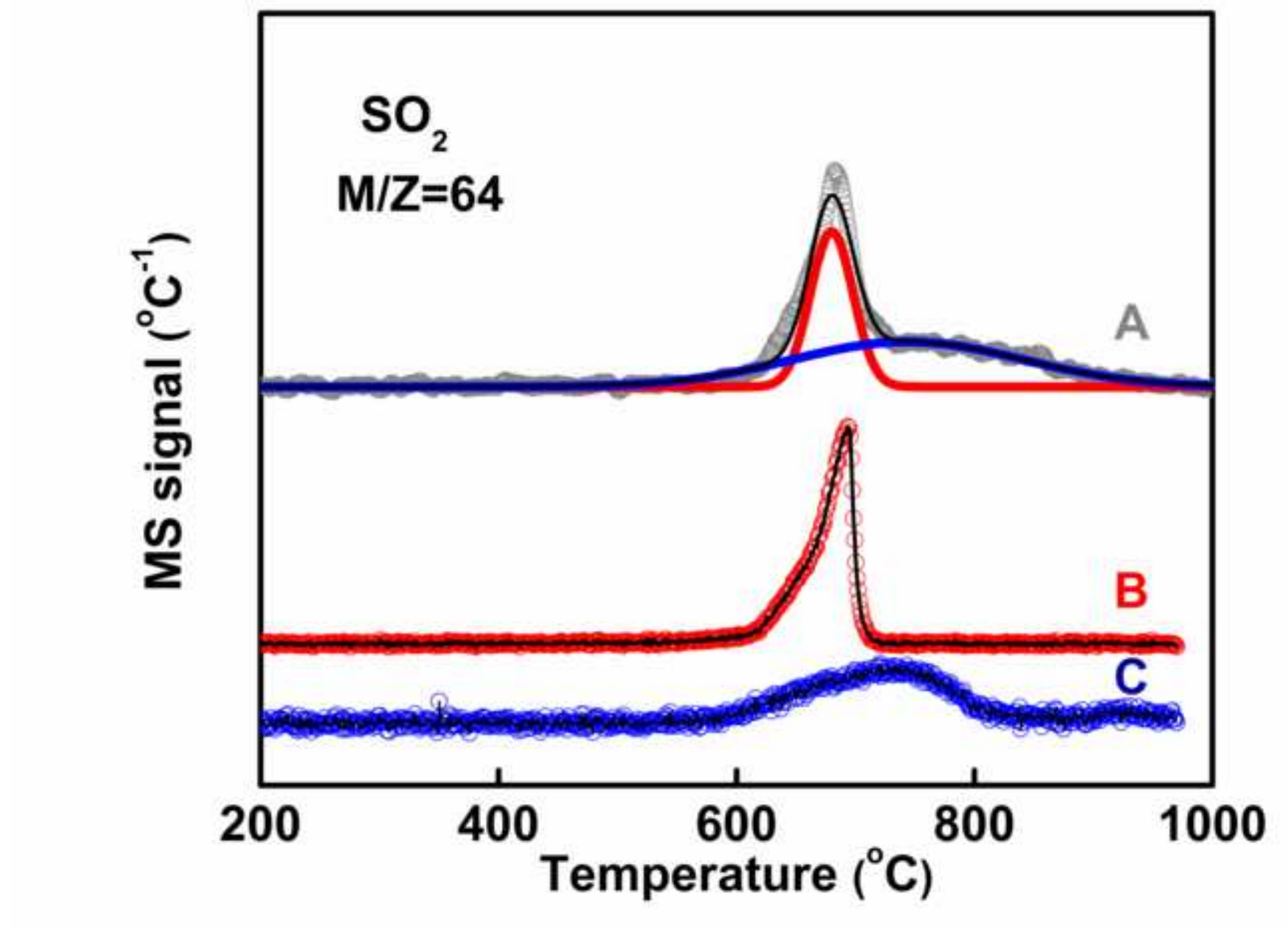

$\mathrm{SO}_{2}$

.




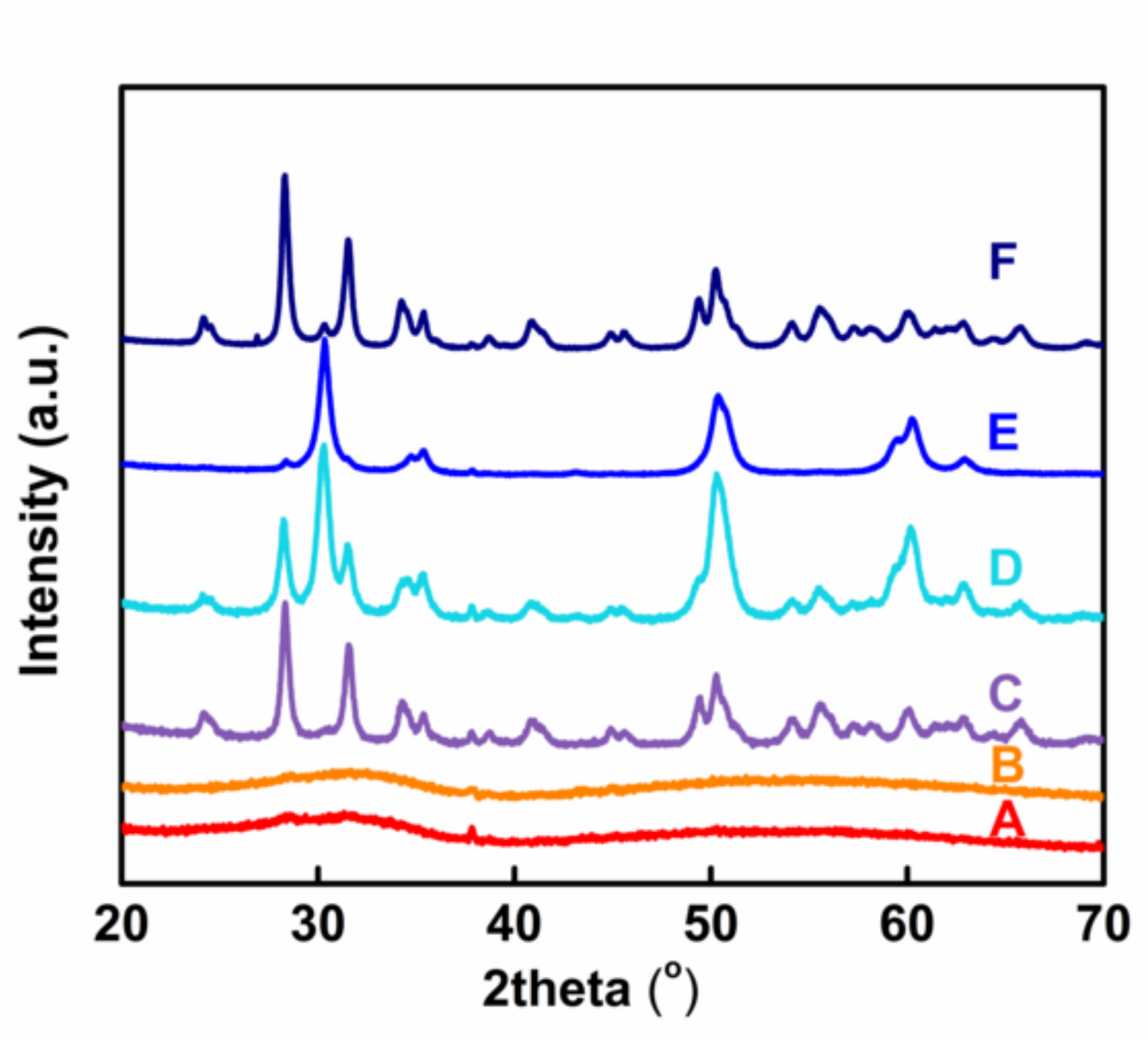

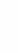




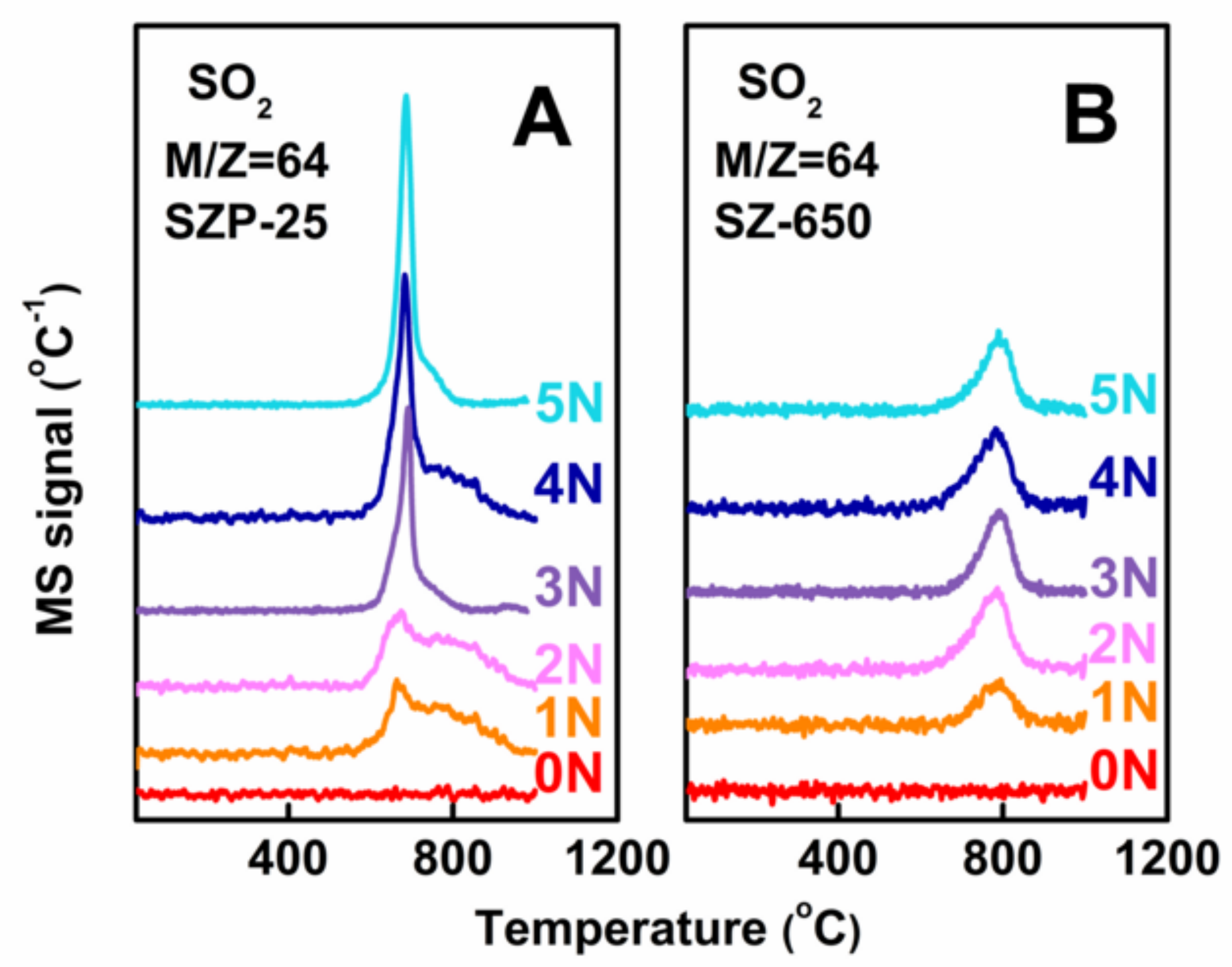




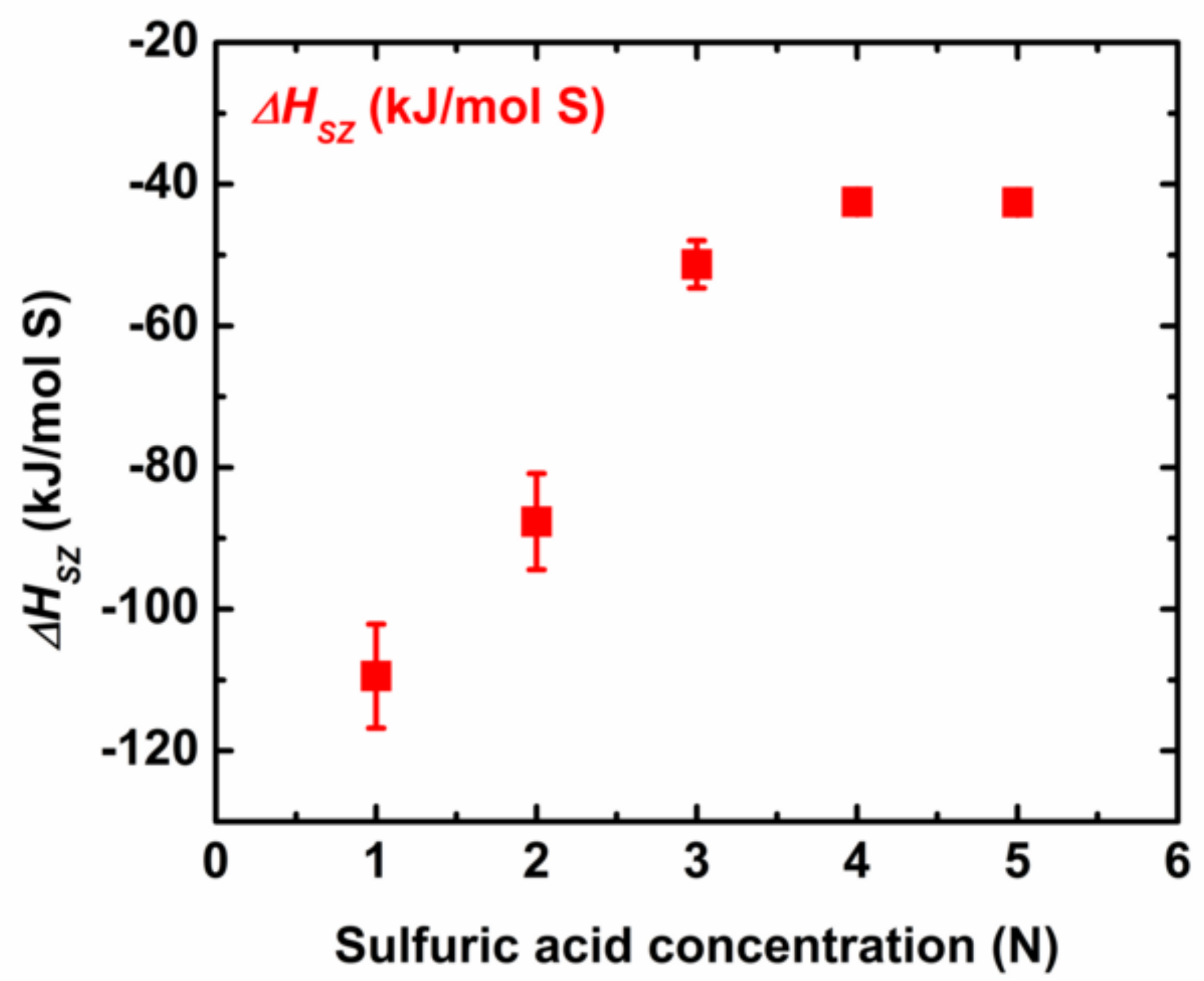




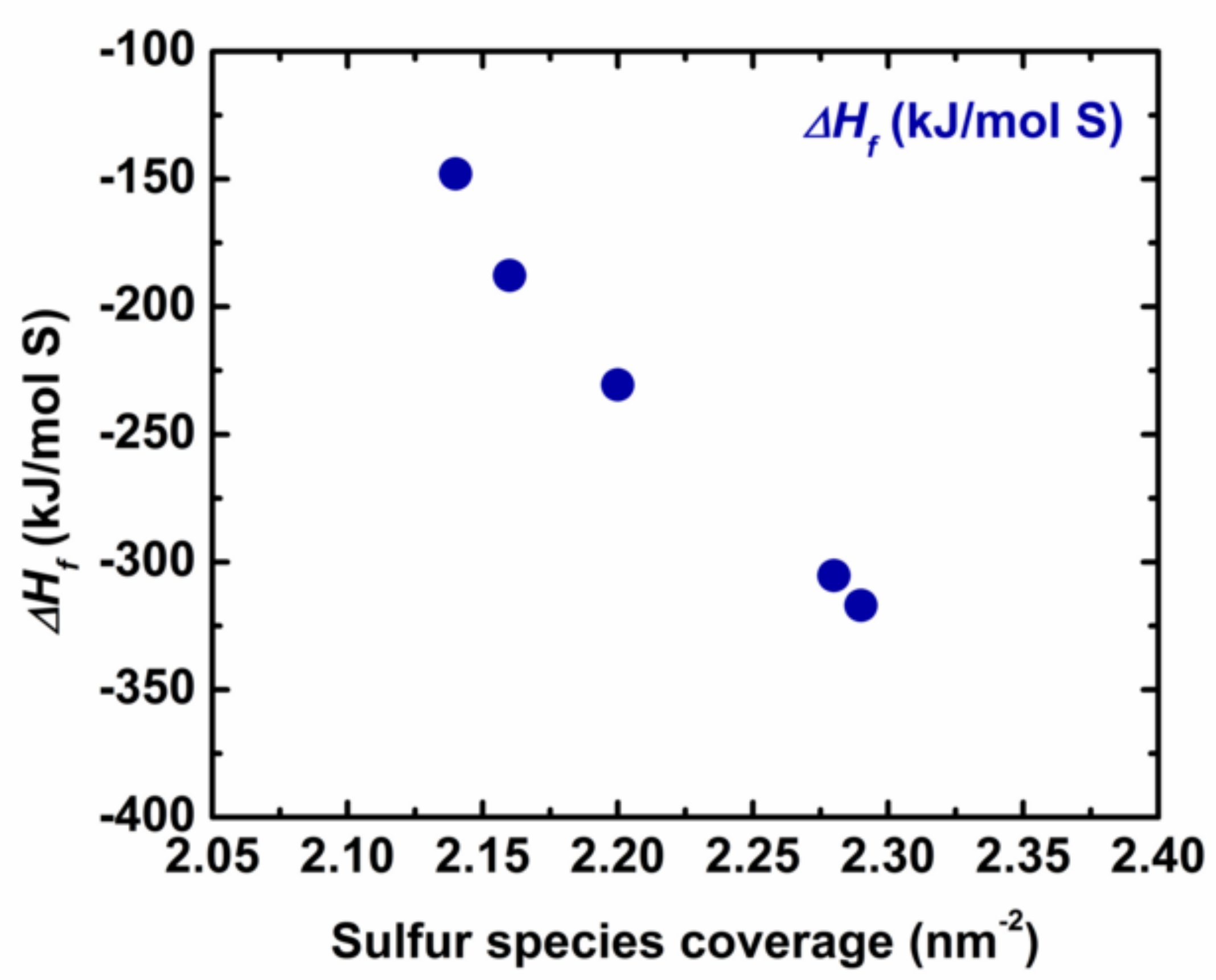




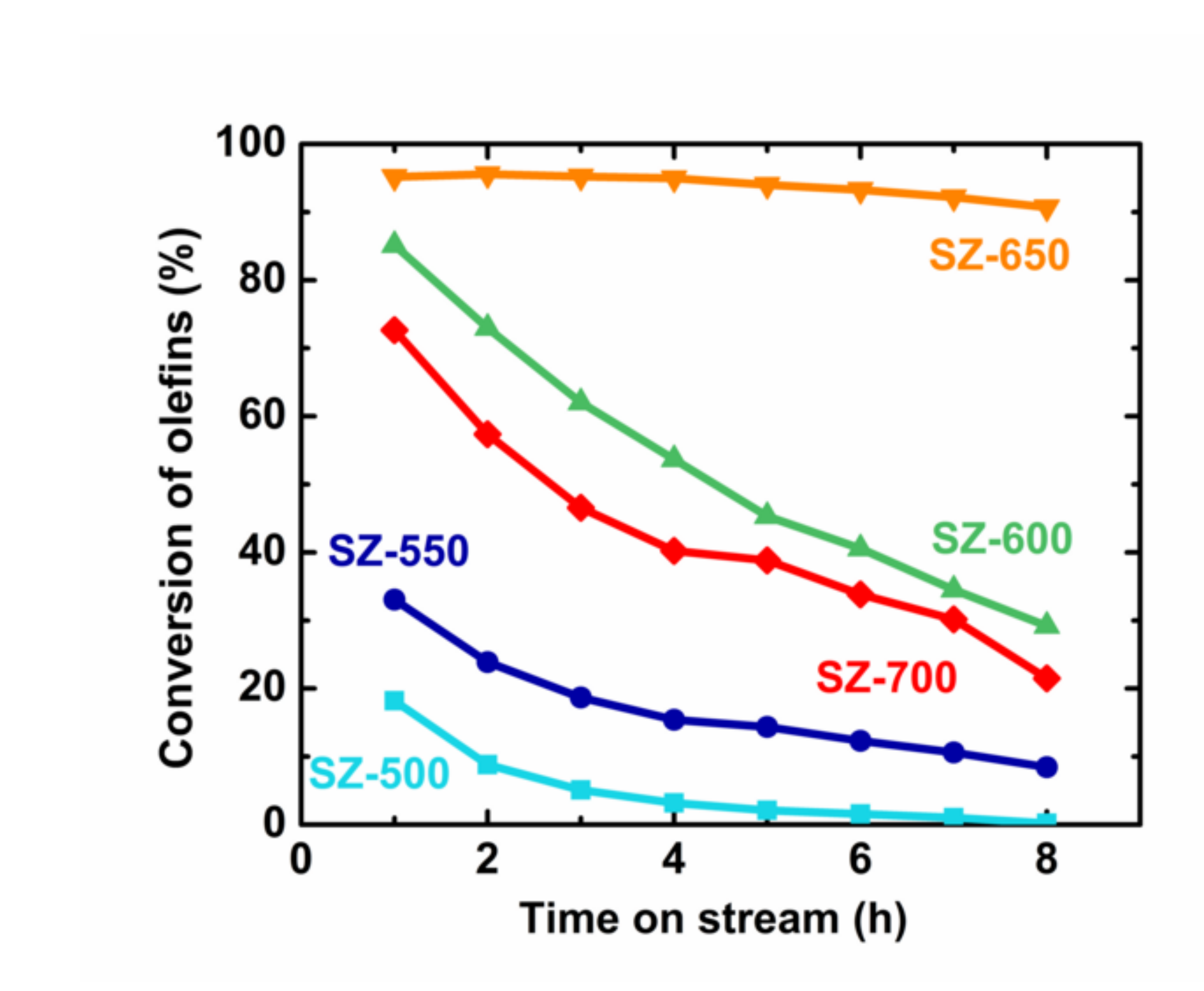

Time on stream (h)

.

.

.

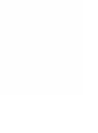

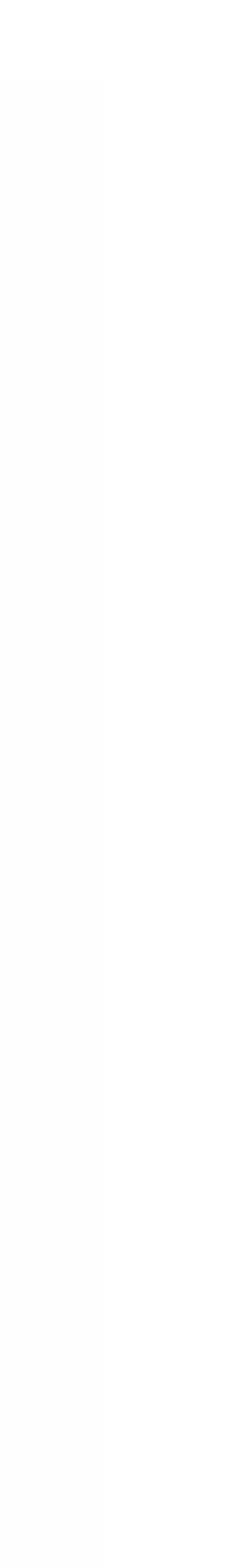

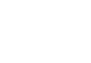
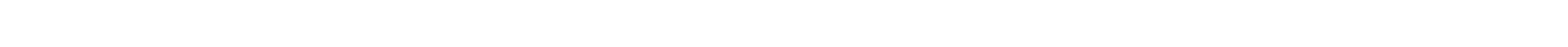


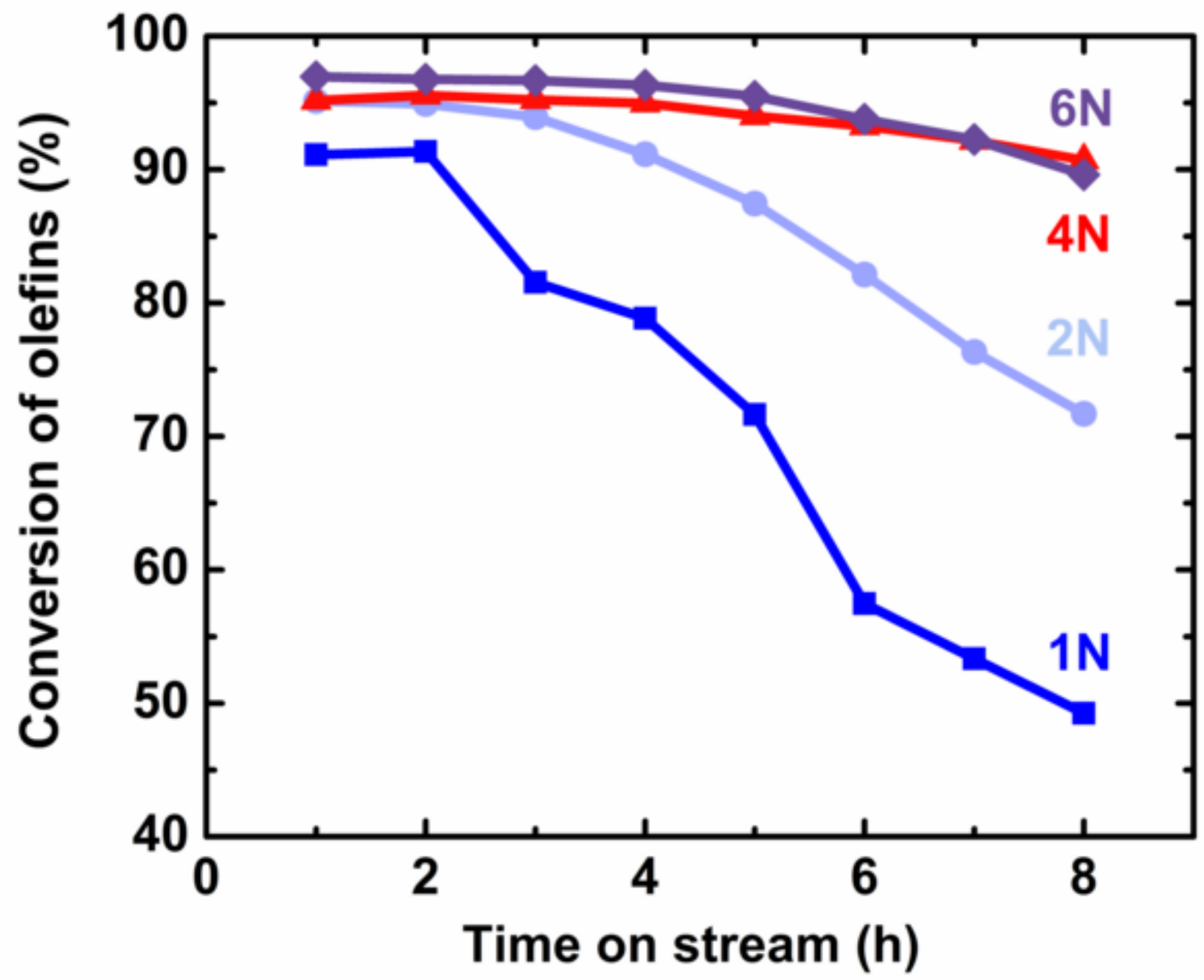


